\title{
O LUGAR DO DESEJO NA MATRIZ DE IDENTIDADE
}

\author{
José Fonseca ${ }^{1 *}$ (iD
}

\section{RESUMO}

O texto considera as raízes etimológicas da palavra "desejo". Discute abordagens filosóficas do conceito e expõe contribuições psicanalíticas. Destaca o lugar do desejo dentro da concepção relacional de Moreno, dando ênfase à matriz de identidade. Leva em conta o desejo e suas circunstâncias: o desejo e a memória, o desejo e a linguagem, o desejo e a demanda, o desejo e a falta, o desejo e a dependência. Discutem-se as implicações, do ponto de vista terapêutico, de trazer à consciência os elementos inconscientes do desejo. Isso facilitaria ao sujeito desatar os seus nós e redirecionar suas demandas.

PALAVRAS-CHAVE: Desejo; Demanda; Psicanálise; Psicodrama.

\section{THE PLACE OF DESIRE IN THE MATRIX OF IDENTITY}

\section{ABSTRACT}

The text considers the etymological roots of the word "desire". It discusses philosophical approaches to the concept and presents psychoanalytic contributions. It highlights the place of desire within Moreno's relational conception, emphasizing the matrix of identity. It takes into account desire and its circumstances: desire and memory, desire and language, desire and demand, desire and lack, desire and dependence. The implications, from a therapeutic point of view, of bringing to consciousness the unconscious elements of desire are discussed. This would make it easier for the subject to untie his knots and redirect his demands.

KEYWORDS: Desire; Demand; Psychoanalysis; Psychodrama.

\section{EL LUGAR DEL DESEO EN LA MATRIZ DE IDENTIDAD}

\section{RESUMEN}

El texto considera las raíces etimológicas de la palabra "deseo". Discute enfoques filosóficos del concepto y presenta contribuciones psicoanalíticas. Destaca el lugar del deseo dentro de la concepción relacional de Moreno, enfatizando la matriz de identidad. Tiene en cuenta el deseo y sus circunstancias: deseo y memoria, deseo y lenguaje, deseo y demanda, deseo y carencia, deseo y dependencia. Se discuten las implicaciones, desde un punto de vista terapéutico, de traer a la conciencia los elementos inconscientes del deseo. Esto facilitaría que el sujeto desatara sus nudos y redirigiera sus demandas.

PALABRAS-CLAVE: Deseo; Demanda; Psicoanálisis; Psicodrama. 


\section{INTRODUÇÃO}

Inseparável do amor, o desejo é, em primeiro lugar, e desde sempre, o desejo do que não podemos possuir. Roudinesco (2019, p. 94)

Este texto foi inspirado em discussões do Grupo de Estudos de Psicodinâmica (GEP) do Daimon — Centro de Estudos do Relacionamento sobre o conceito de desejo. Nossa intenção, como sempre, era a de integrar conceitos psicodinâmicos à psicologia relacional inspirada em Jacob Levy Moreno e Martin Buber (1977). O estudo do desejo interessa para a compreensão do processo relacional. "O juízo que o homem faz de suas ações não pode mais deixar de considerar a questão do desejo, mesmo que ele seja inconsciente” (Scotti, 2012, p. 59).

A palavra desejo vem do latim: desiderium, de siderum. De significa "movimento" e siderum, "sideral", relativo aos astros, às estrelas, ao céu, dando a entender o desejo de algo distante e cósmico. Alguns associam esse significado ao costume de, na observação de uma estrela cadente, formular um pedido (desejo). Já o Dicionário Houaiss da Língua Portuguesa (Instituto Antonio Houaiss, 2001, p. 974) lista alguns significados, entre eles:

aspiração humana de preencher um sentimento de falta ou incompletude; segundo Sigmund Freud, moção psíquica que procura restabelecer a situação da primeira satisfação; expectativa consciente ou inconsciente de possuir (um objeto) ou alcançar (determinada situação que supra uma aspiração do corpo ou do espírito); ambição incontrolável ou excessiva, cobiça, sede; instinto físico que impulsiona o ser humano ao prazer sexual, atração física, lubricidade, excitação.

Como vemos, o conceito de desejo é amplo e impossível de ser alcançado somente por meio de um recorte psicológico. A filosofia sempre se preocupou em refletir sobre o tema. Platão, Espinosa, Hegel, Nietzsche, Deleuze e outros expressaram suas opiniões. Destaco a visão espinoseana, que entende o desejo como uma potência humana, algo que o moralismo religioso procurou coibir. As religiões da época de Espinosa, sobretudo o judaísmo e o cristianismo, temiam seu descontrole e tentavam colocar-lhe um freio por meio da culpa e da penitência. Deleuze, um espinosista, afirma que nada faltaria ao desejo. Critica a versão psicanalítica que o coloca como uma manifestação da falta. Isso, para ele, induziria o sujeito a uma atitude de resignação.

É importante distinguir, então, o desejo consciente, que diz respeito “à vontade, disposição para alguma coisa, anseio, aspiração, cobiça, apetite, concupiscência (tesão e outros significados)” (Almeida, 2017, p. 53), do desejo inconsciente, que veremos abaixo.

\section{O DESEJO NA PSICANÁLISE}

A psicanálise situa o desejo na dimensão do inconsciente. Freud (1996/1895; 1996/1900), desde seus primeiros escritos, colocou a origem do desejo nas experiências de satisfação da criança. Ele distinguiu o desejo da necessidade. Esta transcorre dentro de um circuito corporal, que envolve desprazer, tensão (excitação), descarga e prazer. A memória (traços mnêmicos) das satisfações vividas aguarda sua revivência. Os sonhos, os atos falhos e os chistes expressam a realização inconsciente de desejos recalcados. O trabalho de Freud com pacientes histéricas demonstrou que os sintomas conversivos escondiam desejos inconscientes. O recalque guarda uma força propulsora: o desejo. Assim, o desejo se diferencia da necessidade (consciente) e ganha um status inconsciente.

Lacan integra o conceito filosófico do desejo à teoria do inconsciente freudiano e articula a relação entre a necessidade, a demanda e o desejo. Acrescenta que é a partir do Outro que o sujeito orienta seu desejo. Considere-se que o Outro primordial é composto pela internalização de figuras de suas funções materna, paterna e fraterna. O sujeito espera ser desejado pelo Outro: "o desejo do desejo do Outro". 
Assim, o cuidador do bebê deixa de ser um simples outro para ganhar uma representação inconsciente específica. Distingue-se o "outro”, grafado com “o” minúsculo, do “Outro”, “o grande Outro”, pleno de significantes psicológicos.

Por sua intervenção, o outro, portanto, refere imediatamente a criança a um universo semântico e a um universo de discurso que é o dele. Deste ponto de vista, o outro que inscreve a criança neste referente simbólico investe-se, por sua vez, junto à criança, como um outro privilegiado: o Outro. (Dor, 1989, p. 144)

Mutatis mutandis, do ponto de vista da relação $\mathrm{Eu}-\mathrm{Tu}$, diferencia-se um "Tu" qualquer de um "Tu" grafado com letras maiúsculas, o grande "TU".

A demanda mantém uma relação dialética com o desejo. Assim, como a necessidade busca uma gratificação biológica, a demanda espera uma compensação psicológica. Ela está direcionada a alguém: "A demanda coloca em cena o outro que tem [ou teria] o que me satisfaz" (Rego, 2010, p. 51). Lacan (2003/1961-1962, p. 352) amplia a questão dizendo que "para que a demanda seja demanda, a saber, que ela se repita como significante, é preciso que ela seja decepcionada”.

O desejo constitui um movimento desencadeado pelo impulso de buscar algo. O desejo aponta para um objeto imaginário. A dimensão lacaniana do desejo está ligada a uma falta que não pode ser preenchida por nenhum objeto real, chamado de objeto a. $\mathrm{O}$ objeto a ${ }^{1}$ seria o objeto eternamente faltante, responsável pela presença de um vazio relacional. Esse vazio circunscreve um lugar a ser ocupado por um objeto que será sempre substitutivo de algo faltante. "O objeto a é um objeto faltoso, ou, nos dizeres de Freud, para quem o encontro do objeto é sempre um reencontro, é um objeto perdido que o sujeito busca reencontrar" (Jorge, 2005, p. 139).

Outro ponto importante nessa formulação é que a triangulação, a quebra dual pelo terceiro, funciona como um processo de maturação do desejo. Ela delimita e discrimina a proibição da permissão, o que se pode e o que não se pode ter e ser. Em outras palavras, o processo triangular, em linguagem psicanalítica, "ensina" a lidar com a proibição do incesto e o desejo da morte do pai.

A busca do desejo é bem representada pela topologia lacaniana na figura do toro. Ele é representado por uma mola circular unida pelas extremidades no formato de um pneu. Cada anel circular representa uma demanda insatisfeita que sempre retorna. O espaço vazio dentro da espiral configura o desejo².

Existe um aspecto relacional na contextualização lacaniana do desejo. Assim, Silva (2007, p. 129) o descreve:

No nível da demanda, há, entre o sujeito e o Outro, uma situação de reciprocidade, ou seja, tanto o desejo do sujeito depende inteiramente de sua demanda ao Outro, como o que o Outro demanda também depende do posicionamento do sujeito.

Falar em desejo, portanto, é falar em amor, prazer, satisfação, sexualidade; enfim, em felicidade. Entretanto, fica também implícito que a privação, a frustração e a interdição do desejo geram tristeza, ódio, ciúme, inveja etc.

Se a demanda e o desejo constituem a busca de alguém ou de algo, fica pressuposto que sempre se parte de um vazio a ser preenchido. Mafra (2017, p. 11) diz que, "se o desejo sempre se engana, a demanda é sempre enganada, enquanto o amor sempre engana e se engana”. A propósito, ela cita o filme Esse obscuro objeto do desejo, de Buñuel (1977). Um homem de meia-idade se apaixona obstinadamente por uma jovem, que é representada por duas atrizes (uma espanhola e uma francesa). Quando ele acredita estar próximo de conseguir o desejo do desejo da jovem, acontece uma troca de atrizes de maneira que a ausência persiste e a busca amorosa continua.

Não se pode encerrar este percurso psicanalítico sem falar do conceito de gozo, frequente companhia da demanda, do desejo e de seus consequentes sintomas. Deixemos de lado a confusa conotação de gozo sexual a que ele remete para encontrar seu sentido clínico. Segundo Roudinesco e Plon (1998, p. 299), o gozo contém “a ideia de uma transgressão da

1.Os tradutores de Lacan traduziram "autre" e "Autre" por "outro" e "Outro". Por coerência, a tradução de "objeto a" seria "objeto o".

2. A figura do toro pode ser vista na página 200 do livro Essência e personalidade (Fonseca, 2018). 
lei: desafio, submissão ou escárnio". Ainda segundo esses autores, existe uma obediência do sujeito a uma ordem interna que o leva a "se destruir na submissão ao Outro" (Roudinesco \& Plon, p. 300). O gozo remete a uma tensão entre dois polos que resulta num misto de satisfação e angústia. Existe, por assim dizer, um sofrimento acompanhado de um usufruto deste, como se fosse uma coceira que pode gerar escoriações. O desejo leva ao gozo quando ligado aos excessos, sejam eles de ganância, riqueza, potência, orgulho, inveja ou culpa.

O prazer é consciente, promove relaxamento. O gozo é inconsciente, provoca tensão e pode levar à passagem ao ato. Rego (2010) traduz o gozo como um "grude" que acontece em determinadas relações amorosas, produzindo satisfação e sofrimento concomitantes.

\section{O DESEJO NAS ENTRELINHAS DE MORENO}

Moreno não se dedicou explicitamente a estudar o desejo, mas o conceito está subentendido em sua obra. Percorro, brevemente, alguns conceitos morenianos, levando em conta que, em muitos deles, insere-se tanto o desejo consciente quanto o inconsciente.

Iniciemos pela sociometria, que se propõe a ser a ciência da medida dos relacionamentos humanos, ou, ainda, o estudo da estrutura psicológica da sociedade que subjaz à superfície dos processos sociais. Em outras palavras, ela estuda a rede de escolhas e "desejos" dentro de um grupo. Quem escolho e quem capto (percepto) 3 me escolhe positiva, negativa ou neutralmente. Quem eu desejo e quem eu gostaria que me desejasse? Entretanto, a escolha é a face aparente de um desejo que subjaz inconscientemente. Por isso, as primeiras escolhas, às vezes, revelam-se enganosas no decorrer do tempo. Estamos a falar, por consequência, de outros conceitos morenianos: tele e transferência.

Nas experiências com o teatro da espontaneidade, em Viena, na década de 1920, Moreno constatou que algumas duplas de atores espontâneos durante a ação dramática apresentavam "uma espécie de sensitividade, como se estivessem ligados por uma alma comum”(Moreno, 2008, p. 247). Algo como uma sensibilidade mediúnica. Esse fenômeno relacional constituiria uma empatia de duplo sentido, guiada pelo coconsciente e coinconsciente ${ }^{4}$ dos participantes. A empatia é uma percepção "de mão única”; o tele é uma percepção de "mão dupla”.

O clímax do tele seria um momento de encontro, um impacto existencial com liberação de espontaneidade. Tanto o encontro como o delírio decorrem em estados modificados de consciência, caracterizados por algum tipo de exaltação. A teoria do momento é "inseparável de uma teoria da espontaneidade"(Moreno, 1991, p. 155) e, também, inseparável do conceito de encontro. Cabe lembrar que esperar pelo encontro inclui um desejo justaposto. Porém, não é buscando intelectualmente que se encontra. Acontece...

O desejo está subentendido em um dos conceitos centrais da teoria moreniana: espontaneidade-criatividade-conserva. A psicanálise freudiana liga a criatividade ao conceito de sublimação. A sublimação seria um tipo de defesa madura que transformaria a energia libidinal em ações sociais construtivas. Klein (1997) coloca a posição depressiva como possuidora de uma capacidade de reparação e, portanto, criativa do ser humano. Winnicott (1975) fala de uma criatividade universal inata ao indivíduo. A construção do sujeito aconteceria a partir da interação de sua capacidade criativa com as facilidades/ dificuldades relacionais que lhe são oferecidas pela função materna ("mãe suficientemente boa"). Segundo Pires (2010), a criatividade winnicottiana constitui um potencial humano inato que se manifesta desde a etapa intrauterina e que acompanha a criança no transcorrer de seu desenvolvimento. A criatividade se expressa no brincar e nas atividades lúdicas e culturais. Assim, o viver criativo está sempre presente na saúde emocional do sujeito. A concepção winnicottiana da criatividade aproxima-se da moreniana, em primeiro lugar, porque é eminentemente relacional e, em segundo, porque consiste em aceitar a potencialidade cósmico-criativa do ser humano.

\footnotetext{
3.O teste sociométrico inclui a pesquisa das escolhas de um elemento pelos seus companheiros de grupo, segundo um critério, e pela percepção de quais participantes o escolherão positiva, negativa ou indiferentemente (neutralmente). Esta segunda parte do teste é denominada perceptual.

4. Os conceitos de coconsciente e de coinconsciente constituem um complemento essencial para a compreensão do processo relacional.
} 
Moreno parte do princípio de que o universo é criatividade infinita. A divindade ${ }^{5}$ (macrocosmo) é pleno de espontaneidadecriatividade, responsável pelo constante movimento do universo. A criatura (microcosmo) foi contemplada pelo criador com espontaneidade-criatividade. A criatividade está estrategicamente vinculada à espontaneidade. "Para se tornar efetiva, [a criatividade] necessita (como a bela adormecida) de um catalisador - a espontaneidade" (Moreno, 2008, p. 59). A espontaneidade opera no presente de uma situação relacional. Não existe um reservatório de espontaneidade.

A espontaneidade funciona somente no momento em que emerge, da mesma forma que, metaforicamente falando, quando se acende a luz de uma sala, toda a sala torna-se visível. Quando a luz se apaga, porém, apesar da estrutura básica da sala permanecer a mesma, perde-se uma qualidade fundamental. (Moreno, 2008, p. 56)

\section{MATRIZ DE IDENTIDADE}

A matriz de identidade institui o processo de aprendizagem relacional da criança, ou, em outros termos, o conhecimento do relacionar-se e do separar-se. Ela delineia uma teoria do desenvolvimento infantil. A matriz de identidade estabelece, como o próprio nome diz, a constituição da identidade psicossocial do sujeito. Nela se situa o locus e o status nascendi do desejo.

Ao nascer acontece a primeira inspiração, seguida da primeira expiração. A primeira mamada inaugura o preenchimento do estômago e intestinos. Esses atos instituem os papéis psicossomáticos (papéis de respirador, ingeridor, defecador, urinador etc.), desenvolvidos no relacionamento com os elementos que constituem a função materna.

Inicialmente, a criança não diferencia pessoas de objetos, não distingue fantasia (imaginário) de realidade, vive somente o tempo presente. Depois, discrimina as pessoas e demonstra preferências relacionais. $\mathrm{O}$ bebê caminha de um estado de total indiferenciação para um estado de diferenciação.

Em determinado momento, vivencia a "brecha entre a fantasia e a realidade" (Moreno, 1991, p. 123). Integra os papéis psicossomáticos e os papéis do imaginário com os papéis sociais. Acontece a distinção entre o Eu e o outro, entre o Eu e o Tu. Estabelecem-se o reconhecimento do Eu (estado/posição do espelho), o reconhecimento do Tu e o reconhecimento do Ele (triangulação) ${ }^{6}$ e a incipiente capacidade de inversão de papéis.

Considere-se a indiferenciação a fusão do $E u$ com o $T u$, ainda no ventre materno e nos primeiros tempos de vida. $O$ bebê está submetido a uma dependência absoluta que, aos poucos, torna-se relativa. Ele necessita de cuidadores (posição do duplo) para a sobrevivência. O reconhecimento do Eu ou posição do espelho representa o momento em que a criança integra as partes do seu corpo em uma unidade imaginária que lhe causa a sensação alegre de existir. Ao mesmo tempo se delineia a existência de um Tu que também se revela como outra unidade.

O desenvolvimento tem um movimento de ida e volta, espiralado, que se interpenetra, sem necessariamente seguir uma ordenação cronológica. Os elementos constitutivos da matriz dispõem-se em tempos existenciais que obedecem a uma complexificação gradual, em que os estados anteriores estão contidos nos posteriores. A matriz de identidade está internalizada no adulto como uma estrutura psicossociodinâmica viva, sempre passível de ser acionada, tanto no sentido de influir como no de ser ressignificada ${ }^{7}$. As posições descritas e a triangulação fundamentam as bases psicológicas para a constituição das estruturas psicológicas do futuro adulto ${ }^{8}$.

5.Segundo Regina Moreno (2021), sua filha, Moreno não utilizava a palavra Deus, e sim Divindade (Godhead). "However, J. L.'s vision of the Godhead was non-denominational and more than that, non-religious" (ibidem, p. 16).

6.Ver Capítulo 7, “Onde está o reconhecimento do Ele na matriz de identidade?” (Fonseca, 2018).

7.Distingo a rematrização da ressignificação. A primeira acontece ainda na vigência da matriz de identidade e a segunda, no transcorrer da vida ou de uma psicoterapia. Para melhor esclarecimento, consultar Fonseca (2020).

8.Considerem-se as estruturas psicológicas não trianguladas (psicóticas) das trianguladas (neuróticas). 


\section{O ESPELHO EM MORENO E LACAN}

A posição do espelho, descrita tanto por Moreno como por Lacan, realiza uma ponte entre a psicodinâmica psicanalítica e a psicossociodinâmica relacional. O espelho foi descrito por Lacan oralmente em 1936 e publicado em 1949 (Lacan, 1998) e pelos Morenos (Florence e Jacob Levy) em 1944 e em 1946 (Moreno, J. L. e Moreno, F., 1991). Eles descrevem o espelho como o momento em que a criança expressa a alegria por reconhecer-se como uma unidade psicológica $(\mathrm{Eu}) \mathrm{em}$ relação a outra (Tu). A apreensão que o Eu realiza de si mesmo é referenciada por um Tu (função materna) adulto, que o significa ("você é isto, aquilo e aquilo outro"). O reconhecimento do Eu não acontece por si só, mas na contingência de um Tu. Essa circunstância relacional se desenvolve numa troca de expectativas que instaura a função do imaginário (fantasia).

"Nessa primeira fase de constituição do desejo, que é a fase do imaginário, o desejo ainda não se reconhece como desejo, é no outro ou pelo outro que esse reconhecimento vai se fazer..." (Garcia-Roza, 1993, p. 146).

O desejo do Eu pelo Tu se manifesta como um desejo de ser amado pelo Tu. Assim define-se o postulado que o desejo só pode ser concebido em relação ao desejo do outro: "Desejar o desejo do outro, eis o que caracteriza o Eu como Eu humano" (Garcia-Roza, 1993, p. 142). Porém esse fato não é o término, necessariamente, do processo do desenvolvimento. Ele implica uma sequência de experiências imaginárias que desembocam na função simbólica do reconhecimento do Ele (Fonseca, 2018). Essa nova posição instituirá psicologicamente o discernimento entre o que se pode e o que não se pode ter e ser.

\section{MATRIZ DE IDENTIDADE, A INSERÇÃO COSMO-BIOLÓGICA E A MEMÓRIA}

A concepção significa a inserção de um novo ser em uma teia relacional familiar, situada em uma cidade, em um país, em um continente, no planeta Terra, na Via Láctea, no Cosmo. Por isso, Moreno diz que o ser humano é biopsicossociocósmico.

A partir da relação do espermatozoide com o óvulo, uma série de intercâmbios genéticos, bioquímicos, moleculares, hormonais e ambientais acontece. E continua acontecendo entre o embrião/feto e a mãe. Não existe suficiência neurológica para o registro de traços mnêmicos, ou seja, não há memória evocativa. Não há também a consciência de si, nem a noção do tempo. O novo ser, apesar de indiferenciado, recebe inscrições que poderiam ser chamadas de organísmicas9.

Utilizo a conhecida metáfora da caixa-preta dos aviões para explicar a memória. Ela registra todos os dados do voo: partida, decolagem, subida, voo cruzeiro, descida, aterrissagem ou pouso. Se considerarmos a criança o piloto de nosso estudo, ela não estaria programada geneticamente para lembrar da partida (concepção), da decolagem (vida uterina) e de parte da subida do seu voo (primeiros meses de vida). Ela teria capacidade evocativa somente da subida e do voo cruzeiro, incluindo a descida e o pouso (senectude e morte). Falamos, então, de uma primeira "memória”, oculta, e de uma segunda, resultante da organização de traços mnêmicos gravados a partir, aproximadamente, dos dois anos de idade.

Calegaro (2011), no livro O novo inconsciente, comenta que existem vários sistemas cerebrais distintos responsáveis pela memória. As pesquisas neurofisiológicas consideram que existem fatores biológicos que nunca se tornam conscientes. A memória explícita, declarativa, refere-se a um episódio prévio. A memória implícita, não declarativa, também atribuível ao passado, não apresenta lembrança consciente, e abrange um território mais amplo do que o do inconsciente freudiano, sempre ligado aos conflitos sexuais.

Ainda sobre a memória, cabe lembrar que Bowlby (1983) fala de uma memória episódica, referindo-se ao fato acontecido, e de uma memória semântica, que constitui o arranjo psicológico que o sujeito faz do episódio, segundo suas necessidades de defesa do ego.

Durante a gestação, o pequeno ser tem a satisfação de suas necessidades. O que é necessário lhe é dado. Porém, permanecer, indefinidamente, no útero seria sua morte. $\mathrm{O}$ ato do nascimento, o parto ${ }^{10}$, um trabalho compartilhado com a mãe, representa o fim desse estado. O nascimento encerra a sensação de "não falta" anterior. Abre as portas para um vazio que será preenchido pelo exercício dos papéis psicossomáticos (de respirador, de ingeridor etc.), psicológicos e

9.A epigenética (além da genética) estuda os mecanismos moleculares envolvidos na interação de modulações gênicas com o ambiente.

10.O parto representa a "partida" de um lugar para outro. 
sociais. Desenvolve-se a capacidade lúdica do brincar. Moreno acentua que essa característica seria uma tentativa de colocar novamente dentro de si algo que se perdeu. "A ansiedade é cósmica; o medo é situacional. A ansiedade é provocada por uma fome cósmica de manter a identidade com o universo total (talvez de restaurar a identidade original do bebê na matriz de identidade)" (Moreno, 2014, p. 210).

Pode-se associar o estado de indiferenciação (uterino) ao conceito de "a Coisa” (“das Ding”) de Freud, depois retomado por Lacan. Freud descreve a origem do ser humano em uma dimensão indizível, que não consegue ser nomeada. Segundo o criador da psicanálise, "algo que pertence ao próprio núcleo da natureza" (Freud, 1950/1996, p. 336).

Enfim, por "coisa" entenda-se um vocábulo "coringa”, indeterminado, que pode substituir o que quer que seja (pois às vezes não sabemos exatamente o que nos falta... mas sabemos que algo, alguma coisa, faz falta ... algo me falta, logo desejo, logo existo. (Goldgrub, 2009, p. 8)

Concluindo, existe um vazio fundante que provém da perda da vivência de não falta uterina e uma falta consequente das relações-separações durante a vigência da matriz de identidade. Há uma busca de reencontro com um TU cósmico perdido. O reencontro verdadeiro acontece quando o círculo do eterno retorno se fecha (a morte). Assim, o dito bíblico "porque você é pó e ao pó voltará” (Bíblia Sagrada, 2021, Gên. 3:19) estaria completo se se dissesse: "Do cosmo vieste e ao cosmo retornarás”.

\section{OS PAPÉIS E A LINGUAGEM DO DESEJO}

O desejo é nomeado segundo as satisfações, insatisfações e demandas do infante. Acontece uma comunicação entre ele e os elementos que constituem suas funções materna, paterna e fraterna. Desenvolve-se uma linguagem por intermédio de palavras, entonações de voz, gestos, toques e olhares. Acontece um intercâmbio semântico ${ }^{11}$, que institui um idioma familiar que se desdobra em mitos transgeracionais: de nobreza, tragédia, riqueza, inteligência etc.

Cada componente familiar desenvolve também uma linguagem pessoal a partir de sua estrutura psicológica. As estruturas normóticas/neuróticas apresentam uma linguagem diversa das estruturas foracluídas/psicóticas. O neurótico obsessivo expressa o desejo impossível; o histérico, o desejo insatisfeito e o fóbico, o desejo precavido. O desejo do psicótico é expresso pelo delírio.

A aquisição da linguagem torna o sujeito prisioneiro do futuro, cujo papel seria o de propiciar o reencontro com um passado mítico. O paraíso perdido - em que fomos desejados sem o ônus de desejar, mas no qual também não teríamos existido como sujeitos. (Goldgrub, 2009, p. 4)

Em se tratando da teoria psicodramática, não se pode falar de comunicação humana sem incluir os papéis. Os papéis surgem antes de o $\mathrm{Eu}$ (ego, personalidade, estrutura psicológica) estar formado. Os papéis podem ser definidos como "as formas reais e tangíveis que o Eu adulto adota..." (Moreno, 1991, p. 206). O estudo do Eu é realizado pela observação de como o sujeito exerce seus papéis e, consequentemente, como se vincula com seus contrapapéis. No setting terapêutico pesquisam-se a forma e o conteúdo do papel de paciente e de como ele se vincula ao papel do terapeuta. Outro ponto de observação é como o paciente expressa seus papéis internalizados quando dramatiza no cenário psicodramático. "Os aspectos tangíveis do que é conhecido como 'ego' são os papéis com que este opera...” (Moreno, 1991, p. 214). Ainda a esse respeito, Moreno afirma:

Talvez nenhum outro teste para investigar a personalidade seja mais promissor que o "teste de papéis", devido a íntima relação entre o processo do papel e a formação da personalidade, por um lado, e o contexto cultural das situações, por outro. (Moreno, 1991, p. 215)

11.Entenda-se a semântica como o estudo da relação entre significantes (palavras, frases, sinais e símbolos) utilizados para dar sentido (significado) às comunicações humanas. 
Um teste de papéis realizado por Moreno em um grupo de crianças demonstrou que a performance relacional e social delas não se pautava pelos seus coeficientes de inteligência (Q.I.), e sim pela espontaneidade e criatividade no desempenho e na inversão de papéis.

Durante a primeira infância, a criança exerce sua comunicação com os adultos por intermédio dos papéis psicossomáticos (ingeridor, respirador, defecador, urinador e outros). Ao brincar, desempenha os papéis do imaginário (mãe, pai, professora, super-herói). Aos poucos assume seus papéis sociais (estudante, amigo, namorado). Quando adulto, possui um "cacho de papéis" ${ }^{12}$ sociais: psicólogo, professor, colega, amigo, pai, esposo, amante etc., que expressam socialmente sua personalidade.

E o que os papéis têm que ver com o desejo? Como comenta Mario Carezzato (comunicação pessoal, 2021), participante do Grupo de Estudos de Psicodinâmica (GEP) — Daimon, “os papéis constituem a interface entre o desejo e o Outro. Se a personalidade, como máscara, tem duas superfícies, uma voltada para dentro e outra voltada para fora, a externa denomina-se papel”. Os papéis são, portanto, a extensão social e cultural da personalidade. Funcionam como emissários do desejo e da demanda para o Outro (TU).

\section{O INSTINTO E A PULSÃO RELACIONAL}

Ao sentir fome, busca-se instintivamente alimento. Cada espécie segue seus padrões genéticos. Os seres humanos também carregam instintos que são, porém, revestidos de um aspecto relacional. Quando o lactente sente fome, recebe o leite que satisfaz sua necessidade alimentar. Esse procedimento repetitivo e continuado é intermediado por uma relação cada vez mais próxima, intensa e complexa com as pessoas que compõem seu núcleo relacional. A necessidade é uma função biológica ritmada que depende da sensação de fome-desprazer-tensão-satisfação-prazer-relaxamento. $\mathrm{O}$ circuito, em princípio físico, por ser repetitivo, impregna-se de uma representação psíquica relacional. Desenvolve-se então uma pulsão relacional que inclui não somente a satisfação orgânica da fome, mas também o prazer de estar junto e o sofrimento de se separar.

Ao distinguir objetos de pessoas e o parcial do total, o bebê deixa de se fixar somente no seio. Descobre o olhar, o sorriso, o rosto e a pessoa que amamenta. Os registros mnêmicos tornam-se cada vez mais sutis. O que era instinto passa a ser pulsão relacional e o que era necessidade se transforma em demanda e desejo: no desejo do Outro (TU) e no desejo do desejo do Outro (TU) por si.

Surge, assim, um enredo entre o novo ser e o grupo que compõe sua matriz. Os sentimentos e os desejos são trocados reciprocamente. $\mathrm{O}$ que se espera desses pais? $\mathrm{O}$ que se espera desse filho? As expectativas transitam entre ambos os lados. A mãe espera que o repouso pós-mamada do bebê aconteça. Dor (1989, p. 145) comenta que o repouso do bebê após a mamada ganha a condição de um "testemunho de reconhecimento" para a mãe. E se isto não acontece?

\section{O DESEJO E A DEMANDA}

Uma mamada pode ser mais prazerosa do que outra, e já não se trata somente de apreciação do leite ingerido, mas também da qualidade da relação estabelecida. O período intermediário entre as mamadas circunscreve a sensação alternada de recepção e falta. Delineia-se a expectativa imaginária do próximo encontro: que seja tão bom como foi ou como poderia ter sido. O reencontro induz a uma expectativa mútua que caracteriza a relação. Estar com a figura materna de forma prazerosa associa-se a não estar. Nem sempre a sensação de hoje é igual à representação imaginária de ontem. O imaginário abre o espaço para a ilusão, o devaneio, o sonho, a quimera, a fantasia, a alucinação, a utopia.

O desejo fica suspenso entre o encontro, o reencontro e o desencontro. Há um desejo de realização do que está por vir. Ele institui uma cadeia que une o passado, o presente e o futuro.

O desejo e a demanda, durante o desenvolvimento psicológico, estão vinculados ao ato de receber. O papel psicossomático de ingeridor representa simbolicamente essa função. Assim, a alimentação ganha o significado de estar junto. A propósito,

12. Bustos (1990) coloca as funções maternas, paternas e fraternas como pertencentes a um cacho ("cluster”) primário de papéis. 
a etimologia latina da palavra "comer" assinala que cum significa "com" e edere, "comer". Ou seja, comer com alguém, ato consagrado nas refeições familiares, nos almoços de negócios e nos jantares românticos.

\section{O DESEJO E A FALTA}

Se na barriga da mãe nada faltava, agora o "ter" e o "não ter" passam a ser um único processo. Desponta um critério avaliativo que compara o grau de satisfação atingido com o do imaginário desejado. Assim, distingue-se a privação, o que nunca se teve; a frustração, algo que se teve ou que se imaginou ter tido e que agora falta; e a interdição, o que é desejado, mas não permitido.

Alguns autores valorizam a marca mnêmica imaginária do primeiro olhar de aprovação materno, que serviria como parâmetro para as futuras buscas amorosas ${ }^{13}$. Marcel Proust (1982) descreve uma situação que lembra simbolicamente essa circunstância. Era um dia frio e estava cansado. Foi à casa de sua mãe, que não visitava havia muito. Ela lhe ofereceu um chá com biscoitos. Colocou um pedaço de biscoito na boca e sorveu um gole de chá. Foi tomado, inesperadamente, por uma maravilhosa sensação de prazer e plenitude. Ao recuperar-se do momento inebriante, tentou repeti-lo. Procedeu exatamente como antes e nada aconteceu. Tentou uma terceira vez e novamente em nada resultou. Sobrou a esperança de uma próxima vez...

O personagem Knulp, de Hermann Hesse, conversa com um amigo sobre o desejo e a falta, utilizando uma metáfora com os fogos de artifício:

Bolas de luz azuis e verdes que sobem pela escuridão e, no momento do auge de sua beleza, fazem uma pequena curva e acabam. E quando se contempla isso vive-se a alegria e, ao mesmo tempo, o medo: logo vai acabar de novo, e isso faz parte, e é ainda mais belo do que se durasse muito. (Hesse, 2020, pp. 50-51)

Hesse deixa claro que existe um movimento flexível entre o desejo e a falta que introduz um conteúdo lúdico à díade.

\section{O DESEJO E A DEPENDÊNCIA}

A dependência a que se está submetido na vigência da matriz de identidade diminui com o desenvolvimento, mas, de alguma forma, perdura. Não há ser humano independente. O outro, o Outro, o Tu e o TU são constitutivos de nossa identidade. Sempre precisamos de alguém afetiva, social ou comercialmente.

Henry D. Thoreau (1984) realizou uma experiência de independência social no século 19. Passou dois anos, dois meses e dois dias isolado da sociedade. Retirou-se para o campo e construiu sua casa e os móveis com as próprias mãos. Viveu do que plantava ou do que trocava com os vizinhos. Recebia, eventualmente, amigos que o visitavam. Sua tentativa de isolamento e independência foi relativa, na medida em que não a aboliu totalmente. Descreveu a experiência em um livro, Walden, ou a Vida nos Bosques, que se tornou uma apreciada crítica à sociedade moderna e uma apologia à simplicidade. Uma das obras que inspiraram o movimento bippie dos anos 1960.

\section{FINALIZANDO}

Resumo as considerações apresentadas ao longo do texto. O locus e o status nascendi do desejo se situa na matriz de identidade. Lá acontecem as primeiras experiências fundantes deste processo. Ao vir à luz, a relativa passividade do bebê no período gestacional, onde há a provisão das necessidades básicas, é substituída por uma intensa atividade biopsicossocial. Desenvolvem-se os papéis psicossomáticos, os psicológicos (do imaginário) e os sociais. O processo de relação-separação,

13. O portador de estrutura neurótica obsessiva, movido pelo desejo de alcançar a perfeição, aspira encontrar um olhar que confirme essa expectativa. 
estabelecido com as pessoas que compõem a matriz de identidade, constitui a base psicossocial da personalidade. Aí nascem os desejos, as demandas e as faltas.

O pedido e a vontade são conscientes. O desejo e a demanda, como um iceberg, têm uma faceta consciente e outra inconsciente. A psicanálise realça, apropriadamente, o conteúdo inconsciente deles. Muitas vezes, o que se pede é o contrário do que se deseja inconscientemente.

O desejo se manifesta por uma falta ao qual está intrinsicamente ligado. Ele contém a esperança de que a falta seja preenchida e a apreensão de que não seja. Essas expectativas andam juntas e se repetem. Constituem um "jogo" que pode estar em equilíbrio ou em desequilíbrio, tal como expressa o personagem Knulp, de Hesse. O livre desejo seria um ato espontâneo que resulta em criatividade, uma rebeldia às conservas aprisionadas. Ele pressupõe a aceitação da falta como uma nova perspectiva vislumbrada. Como se trata de uma ação, o verbo utilizado é o fazer ("que se opõe ao ser e ao ter") (Goldgrub, 2009). Assim, a arte, por exemplo, seria sempre a tentativa de organizar um vazio. O desequilíbrio no “jogo" entre o desejo e a falta é expressado no "gozo", um misto de prazer e dor, que leva o sujeito a um estado de submissão relacional.

Um dos objetivos da psicoterapia é trabalhar o modo como o sujeito lida com seus desejos e demandas. É ajudá-lo a ter consciência deles e aprender a desatar seus nós. É redirecioná-lo das demandas para a análise delas. Voltar-se para dentro e deixar de buscar fora as supostas dádivas de um TU imaginário. Segundo Fink (2018), o trabalho terapêutico busca trazer à consciência os elementos inconscientes do desejo e que este não se iniba diante do suposto desejo do Outro. Isso permitiria ao paciente "seguir além da neurose" (Fink, 2018, p. 228).

Não posso deixar de citar, como fecho, Fernando Pessoa (1996, p. 91) que, em poucas e curtas linhas, resume a questão:

Sei que nunca terei o que procuro

E que nem sei buscar o que desejo,

Mas busco, insciente, no silêncio escuro

E pasmo do que sei que não almejo

\section{DISPONIBILIDADE DE DADOS DE PESQUISA}

Não se aplica.

\section{FINANCIAMENTO}

Não se aplica.

\section{AGRADECIMENTO}

Não se aplica.

\section{REFERÊNCIAS}

Almeida, W. C. (2017). Elogio a Jacques Lacan. Summus.

Bíblia Sagrada. (2021). Gênesis 3:19. Bíblia Online. https://www.bibliaonline.com.br/nvi/gn/19

Bowlby, J. (1983). La pérdida afectiva: Tristeza y depresión. Paidós.

Buber, M. (1977). Eu e Tu. Cortes \& Moraes.

Buñuel, L. (Diretor). (1977). Esse obscuro objeto do desejo (Filme). Serge Silberman.

Bustos, D. (1990). Perigo... amor à vista! Aleph.

Calegaro, M. M. (2011). O novo inconsciente. ArtMed. 
Dor, J. (1989). Introdução à leitura de Lacan. Artes Médicas.

Fink, B. (2018). Introdução clínica à psicanálise lacaniana. Zahar.

Fonseca, J. (2018). Essência e personalidade. Ágora.

Fonseca, J. (2020, August 14-15). Matriz de identidade: Marilyn Monroe, o menino Lance e o Dr. Greenson [Apresentação de trabalho]. Encontro com Fonseca. Tubarão/SC.

Freud, S. (1996). Projeto para uma psicologia cientifica (Vol. I). Imago. (Obra original publicada em 1895).

Freud, S. (1996). A interpretação de sonhos (Vol. V.). Imago. (Obra original publicada em 1900).

Freud, S. (1996). Edição Standard Brasileira das Obras Psicológicas Completas de Sigmund Freud. Imago.

Garcia-Roza, L. A. (1993). Freud e o inconsciente. Zahar.

Goldgrub, F. (2009). Necessidade, Desejo, Demanda. https://www.franklingoldgrub.com/textos.

Hesse, H. (2020). Knulp: Três histórias da vida de um andarilho. Todavia.

Instituto Antonio Houaiss. (2001). Dicionário Houaiss da lingua portuguesa. Objetiva.

Jorge, M. A. C. (2005). Fundamentos da psicanálise: de Freud a Lacan. Zahar.

Klein, K. (1997). A psicanálise de crianças. Imago.

Lacan, J. (1998). “Estádio do espelho como formador da função do eu”. In Escritos. Rio de Janeiro: Zahar.

Lacan, J. (2003). Seminário 9: A Identificação (1961-1962). Centro de Estudos Freudianos de Recife.

Mafra, T. M. (2017). Desejo, demanda e amor [Manuscrito não publicado]. Toro.

Moreno J. L. (1991). Psicodrama. Cultrix.

Moreno, J. L. (2008). Quem sobreviverá? Daimon.

Moreno, J. L. (2014). Fundamentos do psicodrama. Summus.

Moreno, J. L. \& Moreno, F. B. (1944). Spontaneity theory of child development. Sociometry, 7(2), 89-128. https://doi. org $/ 10.2307 / 2785405$

Moreno,J.L. \&Moreno, F.(1946/1977). Section IV.Principles of spontaneity. Spontaneity theory of child development. pp. 47-150. In Moreno, J. L. Psychodrama. Beacon House.

Moreno, R. (2021). Words of the daughter: A memoir. Lulu.com.

Pessoa, F. (1996). Tabacaria e outros poemas. Ediouro.

Pires, F.A.R.(2010). Criatividade no processo de amadurecimento em Winnicott [Tese de mestrado, Pontifícia Universidade Católica].TEDE.

Proust, M. (1982). No caminho de Swann. Abril.

Rego, R. G. A. (2010). A palavra é um caminho. In C. Saltini \& H. G. Flores (Eds.), Lacaneando: Ideias, sensações e sentidos nos seminários de Lacan. Wak.

Roudinesco, E. \& Plon, M. (1998). Dicionário de psicanálise. Zahar.

Roudinesco, E. (2019). Dicionário amoroso da psicanálise. Zahar.

Scotti, S. (2012). Psicanálise: Uma ética do desejo. Revista de Psicologia, 3(2), 56-60.

Silva, A. N. (2007). Da demanda ao desejo: A função da recusa na anorexia. Psicanálise e Barroco, 5(1), 121-134.

Thoreau, H. D. (1984). Walden: Ou a vida nos bosques. Global.

Winnicott, D. W. (1975). O brincar e a realidade. Imago. 